BMJ Open

Sport \&

Exercise

Medicine

\title{
The relationship of gross upper and lower limb motor competence to measures of health and fitness in adolescents aged 13-14 years
}

Benjamin David Weedon, ${ }^{1,2}$ Francesca Liu, ${ }^{1,2}$ Wala Mahmoud, ${ }^{1,2}$ Renske Metz, ${ }^{1,2}$ Kyle Beunder, ${ }^{1,2}$ Anne Delextrat, ${ }^{1,2}$ Martyn G Morris, ${ }^{1,3}$ Patrick Esser, ${ }^{1,2}$ Johnny Collett, ${ }^{1,2}$ Andy Meaney, ${ }^{1,2}$ Ken Howells, ${ }^{1,2}$ Helen Dawes ${ }^{1,2}$

To cite: Weedon B D, Liu F, Mahmoud W, et al. The relationship of gross upper and lower limb motor competence to measures of health and fitness in adolescents aged 13-14 years. BMJ Open Sport \& Exercise Medicine 2018;4:e000288. doi:10.1136/ bmjsem-2017-000288

Accepted 9 February 2018
Check for updates

${ }^{1}$ Movement Science Group, Oxford Brookes University, Oxford, UK

${ }^{2} 0 x$ ford Institute of Nursing, Midwifery and Allied Health Research (OxINMAHR), Oxford Brookes University, Oxford, UK

${ }^{3}$ School of Life Sciences, Coventry University, Coventry, UK

Correspondence to Benjamin David Weedon; b.weedon@brookes.ac.uk

\section{ABSTRACT}

Introduction Motor competence (MC) is an important factor in the development of health and fitness in adolescence.

Aims This cross-sectional study aims to explore the distribution of $\mathrm{MC}$ across school students aged 13-14 years old and the extent of the relationship of MC to measures of health and fitness across genders.

Methods A total of 718 participants were tested from three different schools in the UK, 311 girls and 407 boys (aged 13-14 years), pairwise deletion for correlation variables reduced this to 555 (245 girls, 310 boys). Assessments consisted of body mass index, aerobic capacity, anaerobic power, and upper limb and lower limb MC. The distribution of MC and the strength of the relationships between $\mathrm{MC}$ and health/fitness measures were explored.

Results Girls performed lower for MC and health/ fitness measures compared with boys. Both measures of MC showed a normal distribution and a significant linear relationship of MC to all health and fitness measures for boys, girls and combined genders. A stronger relationship was reported for upper limb MC and aerobic capacity when compared with lower limb MC and aerobic capacity in boys $(\mathrm{t}=-2.21$, degrees of freedom $=307, \mathrm{P}=0.03$, $95 \% \mathrm{Cl}-0.253$ to -0.011 ).

Conclusion Normally distributed measures of upper and lower limb MC are linearly related to health and fitness measures in adolescents in a UK sample.

Trial registration number NCT02517333.

\section{INTRODUCTION}

Children and adolescents with low motor competence (MC) display decreased fitness and lower physical activity (PA) levels affecting their health and well-being as adults. ${ }^{1-5}$ Interestingly, MC generally improves throughout development, this is not always true with some young people, particularly girls, observing a decline in MC. ${ }^{6}$ The development of MC is not straightforward and can be explained by a number of psychosocial, biological

\section{Summary of new findings}

- Girls aged 13-14 years showed lower levels of health, fitness and motor competence (MC) compared with boys of the same age with effect size ranging from 0.3 to 1.05 .

- First UK study in secondary school adolescents evaluating MC, and health-related fitness measures.

- Our measures of MC are normally distributed across school-aged adolescents at the population level and these measures of MC were significantly correlated to measures of fitness.

\section{How it might impact clinical practice}

- Adds to the knowledge that MC may be a target for improving fitness, health and sporting activity in UK secondary school adolescents particularly girls.

- Need to monitor and measure MC levels across secondary school-aged adolescents at the population level.

- Both upper and lower limb MC related to fitness and health markers and may offer routes to improve sporting activity.

- Supports the need to deliver physical education lessons in gender-specific groups.

and environmental factors. Furthermore, while MC development in young children is affected by biological maturation, practice and opportunity are more influential during adolescence. $^{6}$

The relationship of PA to MC has been extensively explored, but there is less research exploring the impact of MC on PA. ${ }^{6}$ To date, most research has set out to understand this relationship in people who have impairments in their MC and identified a number of factors affecting MC, PA and sporting participation. The literature indicates an association between MC, aerobic and anaerobic fitness, health (body mass index (BMI) and body fat 
percentage) and levels of PA. ${ }^{7-14}$ Fundamental motor skills performed by less coordinated young people, low $\mathrm{MC}$, are known to require greater physical and cognitive effort and can be fatiguing. ${ }^{15}$ Less coordinated individuals are also known to have altered bioenergetics and struggle with reduced performance on aerobic and anaerobic sporting activities affecting enjoyment and self-esteem. ${ }^{1} 61016-20$ Importantly, reduced MC, activity levels and associated comorbidities of low activity are known to persist into adulthood, particularly in adolescents with impaired MC. ${ }^{21-23}$ Considering the suggested relationship of MC to low PA in childhood and the current crisis in physical inactivity in young people, there is a need to determine $\mathrm{MC}$ in young people. Further considering that MC can effectively be trained in school, ${ }^{24} \mathrm{MC}$ should be measured to determine young people who could benefit from interventions to benefit their longterm health and well-being. ${ }^{25}$

With only limited research exploring the hypothesis of MC as being causative, we set out to explore MC in relation to fitness and health markers. PA is known to reduce in young people in secondary school, particularly girls, and so we set out to measure MC in secondary schools. ${ }^{6}$ Furthermore, recent evidence indicates that MC skills which predict health-related fitness measures are inconsistent between ages and genders. ${ }^{26}$ While MC has been studied in a number of countries in secondary school students, ${ }^{6}$ performance and changes over time are known to vary across nations and there is a need to study performance within the context of each nation considering its unique context. ${ }^{26}{ }^{27}$ Therefore, this study measures MC in relation to aerobic and anaerobic fitness and health measures in adolescents aged 13-14 years in the UK for the first time. ${ }^{28}$ With limited evidence to support which MC measures are most appropriate when screening, monitoring and developing interventions across different abilities, age and genders for young people internationally, there is a need to use a mix of measures. ${ }^{26}$ There is a wide range of movement battery tests that assess $\mathrm{MC}$ as a whole or as individual subsections such as manual dexterity, throwing and catching, and balance tasks (static and dynamic), with specific tests for different age groups. ${ }^{29-31}$ Evidence has suggested that measures of overall $\mathrm{MC}$ are invalid due to vast differences in fine and gross MC in a single participant with many tasks not representing normal distributions. These subsections of MC should be assessed separately. ${ }^{32} 33$ Therefore, this study uses normally distributed measures of gross upper and lower limb MC, which are required for sports games and activities associated with $\mathrm{PA}^{34} 35$

This study will (1) describe MC, aerobic and anaerobic fitness and health measures in secondary school students in the UK and then evaluate the extent of (2) gender differences across MC, fitness and health measures, (3) examine the extent of relationships of MC to aerobic and anaerobic power in boys and girls aged 13-14 years and (4) compare the difference in correlation strengths between upper limb MC and lower limb MC with a corresponding health/fitness measure.

\section{METHODS}

\section{Participants and procedures}

This cross-sectional study collected data as part of the Engagement, Participation, Inclusion and Confidence in Sport (EPIC) study (NCT02517333). The data was gathered from three secondary schools in Oxfordshire, which tested all students enrolled in year 9. The age of the students ranged from 13 to 14 years. All testing took place at the respective schools' sports halls, within an allocated physical education (PE) lesson. The participants were split into equal groups and rotated around each station, evaluating MC, anthropometric and fitness measures. A total of 718 participants were tested across three schools (311 girls, 407 boys). After a pairwise deletion of missing values, the total number of participants with completed data points across each variable was above $77 \%$.

Permission was gained from each school's head teachers to recruit participants, and opt-out consent was collected from each participant's parent or legal guardian.

\section{Measures}

Anthropometrics

Each subject was measured for height and body mass, dressed in light sports clothing with shoes on. Data was adjusted by subtracting $1 \mathrm{~kg}$ from each participant's weight to compensate for clothing and $2 \mathrm{~cm}$ from height to compensate for shoes. This method was used due to the time restrictions imposed by the length of the PE lesson and the number of students tested within that time period. Grip strength was measured using a hand-held dynamometer Takei model TKK 5001 (to the nearest 0.1 $\mathrm{kg}$ ). A SECA medical 770 digital floor scale measured body mass (to the nearest $0.01 \mathrm{~kg}$ ) and a Harpenden stadiometer measured height (to the nearest $0.01 \mathrm{~m}$ ). BMI was calculated as mass divided by height squared $\left(\mathrm{kg} / \mathrm{m}^{2}\right)$.

\section{Aerobic and anaerobic measures}

Aerobic fitness was measured using the 20-metre shuttle run test, ${ }^{36}$ which shows good validity when compared with $\mathrm{VO}_{2}$ peak $(\mathrm{r}=0.69 ; F(1,46)=42.54 ; \mathrm{P} \leq 0.001)$ and reliability (intraclass correlation coefficient $($ ICC) $=0.93 ; F(1$, $19)=2.58, P \geq 0.13$ ) when testing large numbers of participants in a field setting. ${ }^{737}$ The test was described to all participants before attempting the test, with a maximum of 15 participants measured simultaneously. Each participant was instructed to run to the $20 \mathrm{~m}$ markers before the beep sounded, then turn and run back to the start position before the next beep. As the test progressed the time between the bleeps became shorter causing the participants to run faster. If the participant was unable to reach the end of the $20 \mathrm{~m}$ distance before the bleep on three consecutive occasions, or they removed themselves from the test their final level and stage completed was recorded as their score. 
The broad jump was used to measure anaerobic power. This test has shown good reliability ( $\mathrm{ICC}=0.94,95 \%$ CI 0.93 to $0.95, \mathrm{P}<0.001)$ and validity, compared with leg extension one repetition $\max (\mathrm{r}=0.79, \mathrm{P}<0.01)$ when measuring large numbers of students in a field setting. ${ }^{38}$ The test required each participant to jump as far as possible from a standing start behind a marked line. Each participant had to land with both feet together. Two attempts were permitted with the longest jum $p$ recorded as their final score.

\section{Motor competence measures}

The alternate hand wall toss was used to measure upper body gross MC. The test required each participant to stand 1 metre away from a wall. Then in an underarm action, a tennis ball was thrown against the wall and caught with the opposite hand. This was repeated for $30 \mathrm{~s}$ with the total number of completed catches recorded as their score. $^{39}$

Single leg stationary hopping was used to measure lower body gross MC. Each participant was instructed to place their hands on their hips and hop as many times as possible on their preferred leg. The total number of correctly maintained hops was counted over $15 \mathrm{~s}^{40}$

\section{Data analysis}

Descriptive statistics were calculated to characterise anthropometric, $\mathrm{MC}$ and health/fitness measures by gender, an unpaired t-test compared gender differen+ces. Graphical and statistical methods (Shapiro-Wilk) were used to explore the normality of distribution for upper and lower limb MC, to take into account, that in large samples, small deviations from normality is revealed by inferential statistical methods, but these have little effect on the results of a parametric test. ${ }^{41}$ Pearson's bivariate correlation was used to assess the association between aerobic, anaerobic and BMI in relation to upper and lower limb MC for boys, girls and combined genders. A comparison of two overlapping correlations based on dependent groups was used to assess differences between correlations. ${ }^{42}$ Hendrickson $e t a l$ 's modification of William's t-test was used to evaluate the differences between dependent correlations, ${ }^{43}$ with $\mathrm{Zou}^{44}$ method used to calculate $95 \%$ CIs. Data analysis was performed using IBM-SPSS v.23 and $\mathrm{R}^{42}$ with significance set at 0.05 , and Cohen's effect size categorised as small $\leq 0.20$, medium $\leq 0.5$ and large $\geq 0.8$.

\section{RESULTS}

Table 1 shows the descriptive statistics for all study participants. The boys showed higher means for MC, fitness, grip strength and height measurements, whereas girls reported higher BMI scores, with no significant difference between weights for boys and girls. Variability was similar for both genders across all measurements. Effect size ranged from medium (BMI $d=0.3$ ) to large (bleep test $\mathrm{d}=1.05$, broad jump $\mathrm{d}=0.91$ ) for gender differences at $\mathrm{P}<0.05$.

Both measures of $\mathrm{MC}$ reported normal distributions, as indicated by histogram and $\mathrm{Q}-\mathrm{Q}$ plots. However, statistical analysis from Shapiro-Wilk test indicated both MC measures were not normally distributed. Due to the limitations of these statistical tests, ${ }^{41}$ the visual representation provided a more robust method for assessing the normality of data.

Pearson's bivariate correlations reported weak to moderate relationships of MC to all measures of health/ fitness (table 2). The strongest correlation for boys was between upper limb MC and aerobic capacity $(\mathrm{r}=0.490$, $\mathrm{n}=310, \mathrm{P}<0.05,95 \%$ CI 0.404 to 0.572 ). The strongest correlation for girls was between lower limb MC and aerobic capacity $(\mathrm{r}=0.378, \mathrm{n}=245, \mathrm{P}<0.05,95 \%$ CI 0.262 to 0.494$)$. The whole group correlation was strongest between upper limb MC and aerobic capacity $(\mathrm{r}=0.571$, $\mathrm{n}=555, \mathrm{P}<0.05,95 \%$ CI 0.453 to 0.572$)$. The weakest correlation for boys $(\mathrm{r}=-0.154, \mathrm{n}=310, \mathrm{P}<0.05,95 \%$ CI -0.035 to -0.280$)$, girls $(\mathrm{r}=-0.190, \mathrm{n}=245, \mathrm{P}<0.05,95 \%$ CI -0.047 to -0.318$)$ and the whole group $(\mathrm{r}=-0.210$, $\mathrm{n}=555, \mathrm{P}<0.05,95 \%$ CI -0.119 to -0.292 ) was of upper limb MC and BMI. Further analysis compared the strength of the correlations of upper or lower limb with

Table 1 Descriptive characteristics

\begin{tabular}{|c|c|c|c|c|c|c|c|}
\hline \multirow[b]{2}{*}{ ( $\mathrm{n}=$ total, \% males) } & \multicolumn{2}{|l|}{ Boys } & \multicolumn{2}{|l|}{ Girls } & \multirow[b]{2}{*}{$P$ value } & \multirow{2}{*}{$\begin{array}{l}\text { Effect size } \\
\text { (Cohen's d) }\end{array}$} & \multirow{2}{*}{$\begin{array}{l}95 \% \mathrm{Cl} \text { of the } \\
\text { difference }\end{array}$} \\
\hline & Mean & SD & Mean & SD & & & \\
\hline Height $(m)(n=701,56.5 \%)$ & 1.66 & 0.09 & 1.62 & 0.07 & $<0.05$ & 0.42 & -0.048 to -0.022 \\
\hline BMI $\left(\mathrm{kg} / \mathrm{m}^{2}\right)(\mathrm{n}=679,57.1 \%)$ & 19.8 & 3.7 & 20.9 & 3.8 & $<0.05$ & 0.3 & 0.523 to 1.669 \\
\hline Hand grip (kg) (n=698, 56.3\%) & 28.6 & 7.1 & 26.1 & 5.1 & $<0.05$ & 0.41 & -3.451 to -1.563 \\
\hline Bleep test (level shuttle) $(n=702,56.8 \%)$ & 7.2 & 2.5 & 5 & 1.7 & $<0.05$ & 1.05 & -2.542 to -1.879 \\
\hline Hopping (number of hops) ( $n=684,56.1 \%)$ & 49 & 12 & 44 & 11 & $<0.05$ & 0.47 & -7.121 to -3.625 \\
\hline $\begin{array}{l}\text { Alternate hand wall toss (number of } \\
\text { catches) }(n=619,55.2 \%)\end{array}$ & 24 & 8 & 17 & 7 & $<0.05$ & 0.79 & -7.562 to -5.012 \\
\hline
\end{tabular}

BMI, body mass index. 


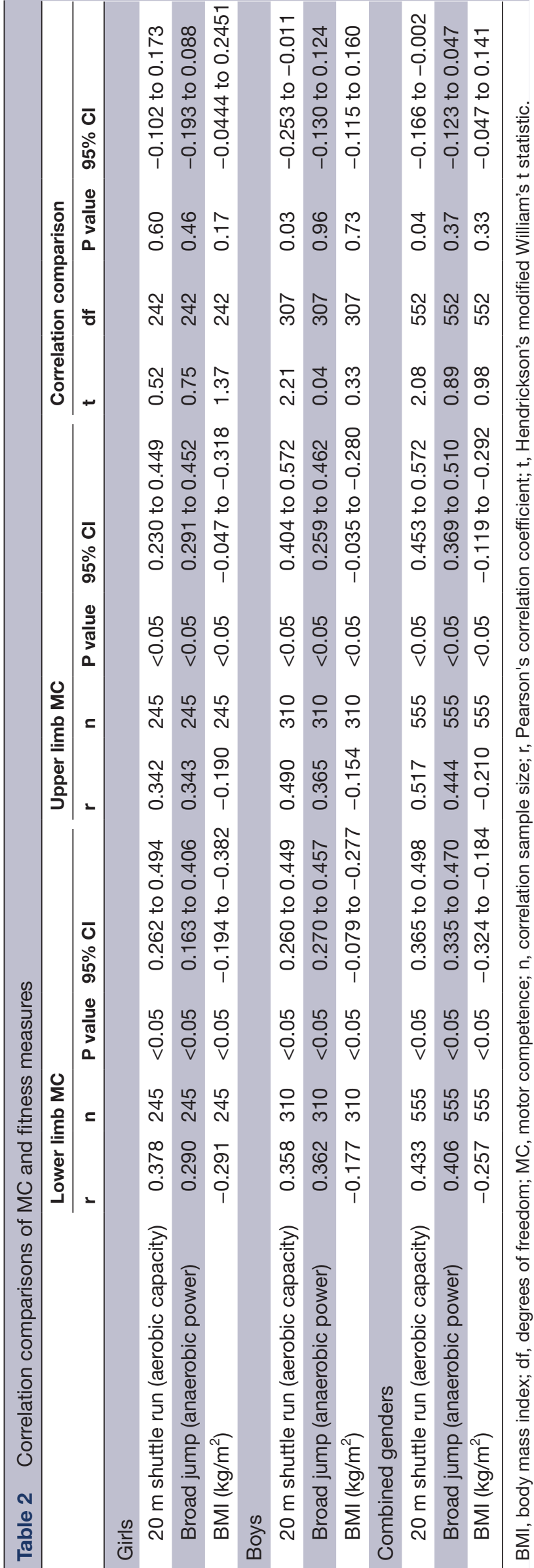

a corresponding health/fitness measure (table 2). The relationship of upper limb MC to aerobic capacity was stronger than that of lower limb MC to aerobic capacity in boys $(\mathrm{t}=-2.21$, degrees of freedom $(\mathrm{df})=307, \mathrm{P}=0.03$, $95 \%$ CI -0.253 to -0.011$)$ and whole groups $(\mathrm{t}=-2.08$, $\mathrm{df}=552, \mathrm{P}=0.04,95 \% \mathrm{CI}-0.166$ to -0.002$)$. All statistical tests produced by $\mathrm{R}$ provided the same conclusions for all correlation comparisons. Girls showed no difference between upper compared with lower limb MC in relation to corresponding health/fitness measures.

\section{DISCUSSION}

For the first time, we observed levels of upper and lower limb MC alongside aerobic and anaerobic fitness and BMI in UK secondary schools. We observed normal distributions for upper and lower limb MC, and a moderate to weak linear relationship of MC to BMI, aerobic and anaerobic fitness. Girls had lower MC, particularly upper limb, strength, aerobic and anaerobic power than boys supporting the need to target girls in this age group. In boys and the whole group, there was a stronger relationship of upper limb compared with lower limb MC to aerobic capacity. Our findings support that both upper and lower limb MC may be a target for improving fitness, health and sporting activity in secondary school adolescents. As a cross-sectional study and considering the low levels of activity and high obesity in UK schools, our findings support an urgent need to investigate the impact of training MC on fitness and health in this age group. ${ }^{45}$

Anaerobic fitness and BMI were similar to previous studies in adolescents of the same age across different nationalities. ${ }^{26}{ }^{27}$ However, comparing aerobic fitness, upper and lower limb MC to previous research has previously proven difficult due to the differences in methods used to measure these movement skills. ${ }^{1426} 46$ This is important as children and adolescents in the UK are reported to be less active compared with other countries. $^{4748}$ Therefore, there is a need to engage more adolescents in higher levels of PA, and understanding the relationship of MC to fitness and health is important in order to promote PA in this age group. ${ }^{45}$

The observed low fitness levels support previous findings that as children progress into adolescence there is a significant reduction in PA and increased sedentary behaviour, particularly in girls. ${ }^{49} 50$ Interestingly, girls also perform significantly lower on both measures of MC. Evidence from a longitudinal study indicated a link between levels of $\mathrm{MC}$ and cardiorespiratory fitness. ${ }^{51}$ Barnett $e t a l^{51}$ evaluated the relationship between MC as measured by object control (throwing, catching, kicking) and locomotor skill (hop, side gallop, jump and sprint) with aerobic fitness. Their results showed MC in elementary school predicted subsequent aerobic fitness in adolescents, with $25.9 \%$ of the variance in fitness attributed to levels of object control. Object control may be a predictor of aerobic fitness in adolescents as a result of greater participation in sports and organised games. These types of activities require high levels of skill in 
controlling or moving an object such as football, netball or hockey ball, which also exposes the participant to levels of higher physical intensities. ${ }^{51}{ }^{52}$ This is important as many PE lessons are predominantly sport-based or game-based activities which require MC. ${ }^{53}$ Therefore, it is important to consider MC skills especially in this age group where PE lessons are in some cases the only mechanism for increasing moderate to vigorous physical activity (MVPA) levels. ${ }^{54}$

This exposure to higher intensities of PA in sports may further explain the difference in upper limb MC compared with lower limb MC in relation to aerobic capacity in the present study. Object control (alternate hand wall toss) was used to measure upper limb MC, whereas lower limb MC used a type of locomotor test (single leg stationary hopping) to measure MC. Therefore, using an object control measure for lower limb MC may produce more valid comparisons, and identify which adolescents require more support in game-based $\mathrm{PE}$ lessons, or conversely may require another activity where these skills do not prevent participation. This could lead to improved engagement and more effective in PE lessons and increased levels of MVPA.

Previous research ${ }^{65}$ showed similar results to other nations and age groups compared with the present study, with significant correlations of upper and lower limb MC to aerobic and anaerobic capacity. ${ }^{64}$ The MC measures consisted of three gross motor tests, one upper limb (ball throwing speed) and two lower body tests (jump distance and ball kicking speed). These relationships may suggest MC plays a role in achieving better levels of health and fitness in school-aged children, but limitations from the cross-sectional study design require caution when making these conclusions. Furthermore, differences in tests used to assess MC and health/fitness between these two studies, and the different age groups used in the previous study (18-25 years) make it difficult to compare these results further. The significant but weak relationship of upper and lower limb MC to BMI is similar to that reported by previous studies. ${ }^{56} 57$ The inverse relationship between BMI and gross MC is suggested to reduce as children age into adolescence, which could be partly explained by growth spurts associated with this age group and limitations with indirect measures of body composition. ${ }^{56}$

The evidence for $\mathrm{MC}$ and its relationship to measures of physical fitness are well documented, 7122031525558 however, there is a lack of consistent measures for MC and relationships to health and fitness across all abilities, ages and genders. ${ }^{12}$ This is highlighted by the vast selection of movement battery tests across the literature. These range from assessments designed to identify clinical deficits in $\mathrm{MC}^{39}{ }^{40}$ to recently created assessments, which incorporate measures from previous assessments designed for typically developed children. ${ }^{31}$ These inconsistencies explain the differences in results and why there is no agreement for an optimal assessment of $\mathrm{MC}^{12}$ Therefore, this study looks to add to the knowledge of both upper and lower limb MC and its relationship to fitness and health with simple measures easily employed in school PE screening.

Our study has a number of limitations including a cross-sectional study design. This limits any conclusion regarding cause and effect between health/fitness measures and MC. In addition, there are limitations to the measurements used when assessing MC and fitness. A systematic review ${ }^{52}$ reported measures for fitness and MC are used interchangeably across different studies. In the present study, standing broad jump was used to measure anaerobic power; however, previous studies have used the standing broad jump to measure lower limb MC. Therefore, measures assessing health/fitness, which also require high levels of $\mathrm{MC}$, would not be an appropriate test when assessing the relationship between these two variables. ${ }^{59}$ Evidence also suggests object control may be a better indicator for associations between MC and fitness. ${ }^{51} \mathrm{MC}$ measures such as hopping, and fitness measures such as the standing broad jump may not be able to detect subtle differences in performance for this population. This indicates a need for future research to evaluate the most appropriate measures of MC and fitness when assessing specific outcomes, for example, age, gender and ability. Further to this, differences in strength of relationship for upper and lower body MC with aerobic capacity may be as a result of different methods used to assess MC. Using object control as a measure for upper limb MC, but not for lower limb MC, may limit further conclusions. BMI has limitations when assessing obesity, especially in adolescents. This measure assesses body composition indirectly and is reported to have low sensitivity. However, it is recommended for screening adolescents at risk of obesity, ${ }^{5}$ and we believe this study has recruited an adequate sample, across whole year groups, from the population to answer the research question. Furthermore, evidence indicates a positive correlation between MC and PA. ${ }^{12}$ This suggests PA may promote $\mathrm{MC}$ in young children which develops into a mutual relationship into adolescents. This indicates a need to control for PA when assessing MC and health/ fitness in future work. ${ }^{26}$

Therefore, this study supports that MC may play an important role in health and fitness in children/adolescents, particularly girls with recommendations that $\mathrm{MC}$ levels be measured and monitored across all abilities, along with direct measures of health and fitness.

Acknowledgements We would like to acknowledge all the hard work from all members of the physical education departments across Cheney School, Wheatley Park School and Cherwell School. We would also like to acknowledge members of the Movement Science Group at Oxford Brookes University for their commitment and support to this study, Catherine Wheatley, Yetunde Dairo, Nolan Tairu, and Tom O'Leary.

Contributors BDW: Main author of the paper, involved with data collection, data analysis and direction of the finished article. FL: Involved in all data collection, and supervised data analysis, with input into the revision of the final article. WM: Led all data collection across all participating schools, advised with data analysis and direction of the article, and with the revision of the final article. RM, KB: Involved in overall data collection and organisation. AD, MGM: Major influence 
of study set-up and design, reviewed article for final submission and critically analysed article for intellectual content and accuracy of overall design. PE: Involved with data collection, data analysis, final approval of article to be published and critically analysing article for overall intellectual content. JC: Involved in data analysis, final draft approval for submission and critical analysis of intellectual content. AM: Involved with data collection, conception and design of the study. KH: Reviewed article for final submission, critically analysed article for intellectual content and accuracy of overall design. HD: Overall control of the study design and implementation, involvement in writing and critical analysis of the overall article, final approval in the submission of the article and its intellectual content, in addition to data collection and analysis.

Funding This work is supported by Community Sports Activation Fund (CSAF, Sport England), PF Charitable Trust, Elizabeth Casson Trust and the NIHR Oxford Biomedical Centre, Health Education England Thames Valley and the CLEAR trust.

Competing interests None declared.

Ethics approval Oxford Brookes University Health and Life Science Faculty Research Ethics Committee granted ethical approval (UREC 140844).

Provenance and peer review Not commissioned; externally peer reviewed.

Data sharing statement Due to ethical approval which does not allow data sharing during or after the study, there is no data that can be shared.

Open Access This is an Open Access article distributed in accordance with the Creative Commons Attribution Non Commercial (CC BY-NC 4.0) license, which permits others to distribute, remix, adapt, build upon this work non-commercially, and license their derivative works on different terms, provided the original work is properly cited and the use is non-commercial. See: http://creativecommons.org/ licenses/by-nc/4.0/

(c) Article author(s) (or their employer(s) unless otherwise stated in the text of the article) 2018. All rights reserved. No commercial use is permitted unless otherwise expressly granted.

\section{REFERENCES}

1. Cermak SA, Larkin D. Developmental coordination disorder: Cengage Learning, 2002.

2. Hands B. Changes in motor skill and fitness measures among children with high and low motor competence: a five-yea longitudinal study. J Sci Med Sport 2008;11:155-62.

3. Jane JY, Sit CH, Burnett AF. Motor skill interventions in children with developmental coordination disorder: a systematic review and meta-analysis. Arch Phys Med Rehabil 2018. doi: 10.1016/j. apmr.2017.12.009. [Epub ahead of print].

4. Kolehmainen N, Ramsay C, McKee L, et al. Participation in physical play and leisure in children with motor impairments: mixed-methods study to generate evidence for developing an intervention. Phys Ther 2015;95:1374-86

5. Rivilis I, Hay J, Cairney J, et al. Physical activity and fitness in children with developmental coordination disorder: a systematic review. Res Dev Disabil 2011;32:894-910.

6. Barnett LM, Lai SK, Veldman SLC, et al. Correlates of gross motor competence in children and adolescents: a systematic review and meta-analysis. Sports Med 2016;46:1663-88.

7. Cairney J, Hay J, Veldhuizen S, et al. Comparison of VO2 maximum obtained from $20 \mathrm{~m}$ shuttle run and cycle ergometer in children with and without developmental coordination disorder. Res Dev Disabil 2010;31:1332-9.

8. Cairney J, Hay J, Veldhuizen S, et al. Assessment of body composition using whole body air-displacement plethysmography in children with and without developmental coordination disorder. Res Dev Disabil 2011;32:830-5.

9. Cairney J, Hay JA, Faught BE, et al. Developmental coordination disorder and overweight and obesity in children aged 9-14 y. Int J Obes 2005;29:369-72.

10. Raynor AJ, Strength RAJ. Strength, power, and coactivation in children with developmental coordination disorder. Dev Med Child Neurol 2001:43:676-84.

11. Schott N, Alof V, Hultsch D, et al. Physical fitness in children with developmental coordination disorder. Res Q Exerc Sport 2007;78:438-50.

12. Robinson LE, Stodden DF, Barnett LM, et al. Motor competence and its effect on positive developmental trajectories of health. Sports Med 2015;45:1273-84.

13. Luz C, Cordovil R, Almeida G, et al. Link between Motor Competence and Health Related Fitness in Children and Adolescents. Sports 2017;5:41.
14. Stodden DF, Gao Z, Goodway JD, et al. Dynamic relationships between motor skill competence and health-related fitness in youth. Pediatr Exerc Sci 2014;26:231-41.

15. Cantell M, Crawford SG, Tish Doyle-Baker PK. Physical fitness and health indices in children, adolescents and adults with high or low motor competence. Hum Mov Sci 2008;27:344-62.

16. Barnett $A L$, Dawes $H$, Wilmut $K$. Constraints and facilitators to participation in physical activity in teenagers with Developmental Co-ordination Disorder: an exploratory interview study. Child Care Health Dev 2013:39:393-403.

17. Capio CM, Sit CHP, Eguia KF, et al. Fundamental movement skills training to promote physical activity in children with and without disability: a pilot study. J Sport Health Sci 2015;4:235-43.

18. Larkin D, Hoare D. Out of step: Coordinating kids' movement: Active Life Foundation, 1991.

19. Liu FK, Morris MG, Dawes H. Physiological and perceptual responses to high and low-intensity exercise in adolescents with movement impairment. Med Sci Sports Exerc 2016;48(5S):1022.

20. Morris M, Dawes H, Howells K, et al. Motor impairment and its relationship to fitness in children. BMJ Open 2013;3:e002909.

21. Cairney J, Veldhuizen S, King-Dowling S, et al. Tracking cardiorespiratory fitness and physical activity in children with and without motor coordination problems. J Sci Med Sport 2017;20:380-5.

22. de Chaves RN, Bustamante Valdívia A, Nevill A, et al. Developmental and physical-fitness associations with gross motor coordination problems in Peruvian children. Res Dev Disabil 2016;53:107-14.

23. Lima RA, Bugge A, Pfeiffer KA. Tracking of gross motor coordination from childhood into adolescence. Res Q Exerc Sport 2017;88:52-9.

24. Lander N, Morgan PJ, Salmon JO. Improving early adolescent girls' motor skill: A cluster randomized controlled trial. Med Sci Sports Exerc 2017;49:2498-505.

25. Logan SW, Robinson LE, Wilson AE, et al. Getting the fundamentals of movement: a meta-analysis of the effectiveness of motor skill interventions in children. Child Care Health Dev 2012;38:305-15

26. Luz C, Rodrigues LP, Meester A, et al. The relationship between motor competence and health-related fitness in children and adolescents. PLoS One 2017;12:e0179993.

27. Gísladóttir $\mathrm{O}$, Haga M, Sigmundsson $\mathrm{H}$. Motor competence and physical fitness in adolescents. Pediatr Phys Ther 2014;26:69-74.

28. Active SAS. A report on physical activity for health from the four home countries' Chief Medical Officers. London: The Department of Health Google Scholar, 2011.

29. Cools W, Martelaer KD, Samaey C, et al. Movement skill assessment of typically developing preschool children: a review of seven movement skill assessment tools. J Sports Sci Med 2009;8:154-68.

30. Hands B, Licari M, Piek J. A review of five tests to identify motor coordination difficulties in young adults. Res Dev Disabil 2015;41:40-51.

31. Luz C, Rodrigues LP, Almeida G, et al. Development and validation of a model of motor competence in children and adolescents. J Sci Med Sport 2016;19:568-72.

32. Deitz JC, Kartin D, Kopp K. Review of the Bruininks-Oseretsky test of motor proficiency, second edition (BOT-2). Phys Occup Ther Pediatr 2007;27:87-102.

33. Kauranen KJ, Vanharanta HV. Relationship between extremities in motor performance. Percept Mot Skills 2001;92:11-18.

34. Lubans DR, Morgan PJ, Cliff DP, et al. Fundamental movement skills in children and adolescents. Sports Medicine 2010;40:1019-35.

35. Morgan PJ, Barnett LM, Cliff DP, et al. Fundamental movement skill interventions in youth: a systematic review and meta-analysis. Pediatrics 2013;132:e1361-83.

36. Léger L, Gadoury C. Validity of the $20 \mathrm{~m}$ shuttle run test with $1 \mathrm{~min}$ stages to predict VO2max in adults. Can J Sport Sci 1989;14:21-6.

37. Liu NY, Plowman SA, Looney MA. The reliability and validity of the 20-meter shuttle test in American students 12 to 15 years old. Res $Q$ Exerc Sport 1992;63:360-5.

38. Fernandez-Santos JR, Ruiz JR, Cohen DD, et al. Reliability and validity of tests to assess lower-body muscular power in children. J Strength Cond Res 2015;29:2277-85.

39. Henderson SE, Sugden DA, Barnett AL. Movement assessment battery for children-2: Movement ABC-2: Examiner's manual: Pearson, 2007.

40. Bruininks RH. Bruininks-Oseretsky Test of Motor Proficiency, (BOT2). Minneapolis, MN: Pearson Assessment, 2005.

41. Ghasemi A, ZahediasI S. Normality tests for statistical analysis: a guide for non-statisticians. Int J Endocrinol Metab 2012;10:486-9.

42. Diedenhofen B, Musch J. cocor: a comprehensive solution for the statistical comparison of correlations. PLoS One 2015;10:e0121945. 
43. Hendrickson GF, Stanley JC, Hills JR. Olkin's new formula for significance of r13 vs. r23 compared with Hotelling's method. Am Educ Res J 1970;7:189-95.

44. Zou GY. Toward using confidence intervals to compare correlations. Psychol Methods 2007;12:399-413.

45. Lima RA, Pfeiffer K, Larsen LR, et al. Physical activity and motor competence present a positive reciprocal longitudinal relationship across childhood and early adolescence. J Phys Act Health 2017;14:440-7.

46. Haga M, Gísladóttír T, Sigmundsson $\mathrm{H}$. The relationship between motor competence and physical fitness is weaker in the 15-16 yr. Adolescent age group than in younger age groups (4-5 yr. and 11-12 yr.). Percept Mot Skills 2015;121:900-12.

47. Tremblay MS, Barnes JD, González SA, et al. Global Matrix 2.0 Research Team. Global Matrix 2.0: report card grades on the physical activity of children and youth comparing 38 countries. $J$ Phys Act Health 2016;13(11 Suppl 2):S343-66.

48. Wilkie H, Standage M, Sherar L. Results from England's 2016 report card on physical activity for children and youth. J Phys Act Health 2016;13(11 Suppl 2):S143-9.

49. Brodersen NH, Steptoe A, Boniface DR, et al. Trends in physical activity and sedentary behaviour in adolescence: ethnic and socioeconomic differences. Br J Sports Med 2007:41:140-4.

50. Dumith SC, Gigante DP, Domingues MR, et al. Physical activity change during adolescence: a systematic review and a pooled analysis. Int J Epidemiol 2011;40:685-98.
51. Barnett LM, Van Beurden E, Morgan PJ, et al. Does childhood motor skill proficiency predict adolescent fitness? Med Sci Sports Exerc 2008;40:2137-44.

52. Cattuzzo MT, Dos Santos Henrique R, Ré AH, et al. Motor competence and health related physical fitness in youth: a systematic review. J Sci Med Sport 2016;19:123-9.

53. Department of Education. Physical education programmes of study: key stages 3 and 4 National curriculum in England, 2013.

54. Calahorro-Cañada F, Torres-Luque G, López-Fernández I, et al. Is physical education an effective way to increase physical activity in children with lower cardiorespiratory fitness? Scand J Med Sci Sports 2017;27:1417-22.

55. Stodden D, Langendorfer S, Roberton MA. The association between motor skill competence and physical fitness in young adults. Res $Q$ Exerc Sport 2009;80:223-9.

56. Lopes VP, Stodden DF, Bianchi MM, et al. Correlation between $\mathrm{BMI}$ and motor coordination in children. J Sci Med Sport 2012;15:38-43.

57. Okely AD, Booth ML, Chey T. Relationships between body composition and fundamental movement skills among children and adolescents. Res Q Exerc Sport 2004;75:238-47.

58. Haga M. The relationship between physical fitness and motor competence in children. Child Care Health Dev 2008;34:329-34.

59. Hands B, Larkin D. Physical fitness differences in children with and without motor learning difficulties. Eur J Spec Needs Educ 2006;21:447-56. 